Reacti ons of excited-st at e benzophenone ketyl radi cal i $n$ a room temper at ure i oni c I i qui d

\begin{tabular}{|l|l|}
\hline 著者 & $\begin{array}{l}\text { Takahashi Kenj i, Tezuka Hi roaki, K t amur a } \\
\text { Shi ngo, Sat oh Toshi f um, Kat oh Ryuzi }\end{array}$ \\
\hline $\begin{array}{l}\text { j our nal or } \\
\text { publ i cat i on t i t l e }\end{array}$ & Physi cal Chemi st ry Chemi cal Physi cs \\
\hline vol une & 12 \\
\hline nunber & 8 \\
\hline page r ange & $1963-1970$ \\
\hline year & $2010-01-01$ \\
\hline URL & ht t p: //hdl . handl e. net /2297/23500 \\
\hline
\end{tabular}


For submission to the themed issue of PCCP,

Influence of Ionic Liquids on Physico Chemical Reactions

\section{Reactions of Excited-State Benzophenone Ketyl Radical in a Room-Temperature Ionic Liquid}

Kenji Takahashi, ${ }^{* a}$ Hiroaki Tezuka, ${ }^{\dagger a}$ Shingo Kitamura, ${ }^{\S a}$ Toshifumi Satoh, ${ }^{\mathrm{b}}$ Ryuzi Katoh ${ }^{\mathrm{c}}$

${ }^{a}$ Division of Material Science, Graduate School of Natural Science and Technology, Kanazawa University, Kanazawa 920-1192, Japan

${ }^{\mathrm{b}}$ Division of Biotechnology and Macromolecular Chemistry, Graduate School of Engineering, Hokkaido University, Sapporo 060-8628, Japan

${ }^{\mathrm{c}}$ National Institute of Advanced Industrial Science and Technology (AIST), Tsukuba Central 5, 1-1-1 Higashi, Tsukuba, Ibaraki 305-8565, Japan

*Corresponding author

Kenji Takahashi

Email: ktkenji@t.kanazawa-u.ac.jp

$\dagger$ Present address: Mitsubishi Chemical Engineering Corporation, Yokkaichi, 510-0863 Japan

${ }^{\S}$ Present address: Canon Inc., Ayase, 252-1124 Japan 


\begin{abstract}
The photochemistry of benzophenone ketyl radical in the $D_{1}$ excited state, $\operatorname{BPH}\left(D_{1}\right)$, was studied by means of two-color dual-pulse laser flash photolysis (355 and $532 \mathrm{~nm}$ ) in a room-temperature ionic liquid, 1-butyl-3-methylimidazolium bis(trifluoromethylsulfonyl)amide (Bmim-TFSA), and in methanol. Upon excitation with the 532-nm pulse, $\mathrm{BPH}\left(\mathrm{D}_{1}\right)$ emitted strong fluorescence. The transient absorption and fluorescence spectra of $\mathrm{BPH}\left(\mathrm{D}_{1}\right)$ were measured with nanosecond and sub-nanosecond time resolution, respectively. The observed Stokes shift was $1700 \mathrm{~cm}^{-1}$ in Bmim-TFSA, and this shift was close to that in acetonitrile. The fluorescence lifetime of $\mathrm{BPH}\left(\mathrm{D}_{1}\right)$ was determined to be $5 \mathrm{~ns}$ in Bmim-TFSA, and again the value was close to that in acetonitrile. The rate constant of the reaction of $\mathrm{BPH}\left(\mathrm{D}_{1}\right)$ with $\mathrm{CCl}_{4}$ in Bmim-TFSA was determined to be $(2.1 \pm 0.4) \times 10^{9} \mathrm{M}^{-1} \mathrm{~s}^{-1}$, which was 10 times the rate constant calculated on the basis of the bulk viscosity of Bmim-TFSA. The results are discussed in terms of the effective microscopic viscosity of the ionic liquid that was recently reported for the cage effect.
\end{abstract}




\section{Introduction}

Ionic liquids (ILs) are receiving much attention as potential green solvents for various chemical processes. Potential applications include their use as electrolytes for electrochemical reactions and as green reaction media for organic reactions including photochemical reactions and photoinduced electron-transfter reactions. ${ }^{1-16}$ Because the photochemistry of benzophenone (BP) has been widely investigated in various organic solvents, ${ }^{17}$ comparing the dynamics of photoinduced reactions of triplet-state $\mathrm{BP}\left(\mathrm{BP}\left(\mathrm{T}_{1}\right)\right)$ and benzophenone ketyl radical $(\mathrm{BPH})$ in ILs with the reaction dynamics in conventional organic solvents can provide information about the solvent characteristics of ILs. For example, Muldoon et al. found that the activation energy for hydrogen abstraction from imidazolium-based ILs (22 to $25 \mathrm{~kJ} / \mathrm{mol}$ ) by $\mathrm{BP}\left(\mathrm{T}_{1}\right)$ is substantially higher than the energies observed in conventional solvents $(13.7 \mathrm{~kJ} / \mathrm{mol}$ in cyclohexane and $14.5 \mathrm{~kJ} / \mathrm{mol}$ in toluene). ${ }^{18}$ The activation energy is independent of the anionic component $\left(\mathrm{PF}_{6}\right.$ or $\left.\left.\left(\mathrm{CF}_{3} \mathrm{SO}_{2}\right) \mathrm{N}\right)\right)$ and the availability of the hydrogen atom at the 2-position of the imidazolium ring.

Recently Wakasa studied the effects of a magnetic field on photoinduced hydrogen-abstraction reactions of $\mathrm{BP}\left(\mathrm{T}_{1}\right)$ with thiophenol in ILs. ${ }^{19}$ The yield of the ketyl radical decreased even when the intensity of the magnetic field was low. The high viscosity of ILs cannot be the reason for this large magnetic field effect, and Wakasa speculated that a cage effect may be important because a confined system is necessary for spin conversion. This speculation is consistent with the recent findings on local structure and domains in ILs, which are unique characteristics of ILs as condensed media. The importance of local structures has been discussed recently. For example, Hamaguchi's group used Raman spectral analysis to show for the first time that two distinct conformational structures of the imidazolium cation exist simultaneously in the IL state. ${ }^{20,21}$ These investigators also obtained evidence of mesoscopic local structure in ILs by means of coherent anti-Stokes Raman scattering measurements. ${ }^{22}$ Iwata et al. investigated the importance of local structures in reaction dynamics by measuring the vibrational cooling rates of the excited state of trans-stilbene in ILs by picosecond time-resolved Raman spectroscopy. ${ }^{23,24}$ The local structure is manifested by the existence of structurally distinct domains of polarity and nonpolarity occupied by the charged (constituent ions) and uncharged parts (side chains) of ILs, respectively. The volumes and interconnectivity of these heterogeneous domains depend on the lengths of the aliphatic side 
chains. ${ }^{25-27}$ The distribution of various solutes between the domains depends on the solute characteristics. Consequently, attempts to characterize the polarity of ILs using solvatochromic probes give disparate answers depending on the probe molecule used. ${ }^{28}$

Many fast bimolecular reactions have been studied in ILs. ${ }^{29-37}$ In general, hydrodynamic approximation of the diffusion coefficient on the basis of the Stokes-Einstein equation is not applicable to diffusion-limited reactions in ILs. Several research groups have suggested that the faster translational diffusion in ILs is due to a large void volume produced by cations and anions. ${ }^{18,34}$ Recently, Kimura's group ${ }^{38,39}$ measured diffusion coefficients of transient radicals in ILs using a transient grating method and found that the diffusion coefficient of BP in ILs is larger than that predicted by the Stokes-Einstein equation. These investigators measured the diffusion coefficients of $\mathrm{BPH}$ and $\mathrm{BP}$ in 1-butyl-3-methylimidazolium bis(trifluoromethylsulfonyl)amide (Bmim-TFSA) to be $(1.30 \pm 0.03) \times 10^{-11} \mathrm{~m}^{2} \mathrm{~s}^{-1}$ and $(3.40 \pm$ $0.09) \times 10^{-11} \mathrm{~m}^{2} \mathrm{~s}^{-1}$, respectively; that is, the diffusion coefficient of the ketyl radical (BPH) is about $1 / 3$ that of the parent molecule (BP). Kimura et al. also found that the ratios of the diffusion coefficient of BP to that of BPH were larger in ILs (2.7-4.0) than in conventional organic solvents (1.4-2.3). The slow diffusion of BPH in ILs was discussed in terms of the fluctuation of the local electric field produced by the surrounding solvent ions.

In the present study, we conducted the first investigation of the reactions of excited-state $\mathrm{BPH}$ in Bmim-TFSA using two-color dual-pulse laser flash photolysis. Because the absorption maximum of BPH is located around $540 \mathrm{~nm}$, measuring the reaction kinetics of excited-state $\mathrm{BPH}$ using a combination of third- and second-harmonic pulses of a Nd-YAG laser is not difficult. In organic solvents, many studies of the $\mathrm{D}_{1}$ excited state of benzophenone ketyl radical, $\operatorname{BPH}\left(\mathrm{D}_{1}\right)$, have been carried out by means of absorption and emission spectroscopies. ${ }^{40-44}$ The dipole moment of $\mathrm{BPH}\left(\mathrm{D}_{1}\right)$ is estimated to be $7 \mathrm{D},{ }^{43}$ which indicates that $\mathrm{BPH}\left(\mathrm{D}_{1}\right)$ is highly polarized. $\mathrm{BPH}\left(\mathrm{D}_{1}\right)$ reportedly decays by radiative and nonradiative relaxations and by unimolecular and bimolecular chemical reaction processes. ${ }^{41-44}$ Cleavage of the O-H bond of $\mathrm{BPH}\left(\mathrm{D}_{1}\right)$, photo-ionization and formation of solvated electrons, and electron transfer from $\mathrm{BPH}\left(\mathrm{D}_{1}\right)$ to $\mathrm{BP}$ have also been reported. These characteristics of $\mathrm{BPH}\left(\mathrm{D}_{1}\right)$ are interesting enough to warrant studying them in the ionic milieu of ILs.

\section{Experiments}


$N, N, N$-trimethyl- $N$-propylammonium bis(trifluoromethylsulfonyl)amide (TMPA-TFSA) and 1-butyl-3-methylimidazolium bis(trifluoromethylsulfonyl)amide (Bmim-TFSA) were purchased from Kanto Chemical Co. (stated purity $>98 \%$ ), along with benzophenone ( $>98.5 \%$ ), methanol (for fluorescence measurement, $>99.7 \%$ ), and $\mathrm{CCl}_{4}$ (for fluorescence measurement, $>99.75 \%$ ). IL samples were prepared in $20-\mathrm{mL}$ sample bottles and dried under vacuum at $60^{\circ} \mathrm{C}$, and then BP-containing IL samples with an initial BP concentration of $\sim 15 \mathrm{mM}$ were prepared. For kinetics measurements, aliquots of dried BP-containing IL samples were placed in screw-capped, 1-cm quartz cuvettes and dried again under vacuum at $60{ }^{\circ} \mathrm{C}$ prior to measurement. The final BP concentrations $(10-11 \mathrm{mM})$ were determined with a UV absorption spectrophotometer (JASCO, V-570). Care was taken to dry the IL because water may accelerate the diffusion of ions. Water content was measured by means of Karl Fischer titration (Mettler Toledo, DL31). The concentrations of water were less than $40 \mathrm{ppm}$. The viscosity of the IL was measured with a viscometer (Brookfield, DV-II+Pro, CP-40).

Figure 1 shows experimental set-up for two-color dual-pulse laser flash photolysis with transient absorption measurements with nanosecond time resolution. The nanosecond transient absorption was measured with a double-pulse Nd-YAG laser (LOTIS TII, LS-2144DC) in which two independent Nd-YAG rods and Pockels cells were installed. The two Nd-YAG rods were excited by a single flash lamp. By changing the Q-switch trigger timing, the time delay between the laser pulses (channels 1 and 2) was controlled with 1-ns time resolution. A fundamental frequency pulse $(1064 \mathrm{~nm})$ from channel 1 was converted into a third-harmonic-frequency pulse $(355 \mathrm{~nm})$ through KTP and KDP crystals. The laser pulse from channel 2 was converted to a second-harmonic-frequency pulse $(532 \mathrm{~nm})$ through the KTP crystal. The typical output energies were about 25 and $50 \mathrm{~mJ}$ for the 355- and 532-nm pulses, respectively. The repetition rate of the Q-switch trigger of the laser was set to $0.5 \mathrm{~Hz}$ so that the sample was well mixed in the cuvette by a magnetic stirrer. Both laser pulses were merged at the front of the sample cell holder by means of dichroic mirrors. A 150-W xenon arc lamp was used as an analyzing light source, and the excitation laser pulses were perpendicular to the analyzing light. The excitation pulses irradiated the sample in the cuvette through a 6-mm circular mask, and the analyzing light passed through 3-mm circular masks. To measure kinetic traces, we used band-pass filters (OPTO-LINE, band width $10 \mathrm{~nm}$ ) to select the analyzing wavelength. The kinetics data were normally measured at $500 \mathrm{~nm}$ because at this wavelength, the scattered light from the 532-nm laser was negligible. Transient signals were collected with a 
fast silicon photodiode (Thorlabs, PDA10A, $150 \mathrm{MHz}$ ) and recorded on a $500-\mathrm{MHz}$ oscilloscope (Tektronix, DPO 7054). Because ILs undergo photodegradation by UV irradiation $^{45}$, the sample and cuvette were renewed every 50 laser shots. We examined the effect of laser irradiation and photodegradation on the transient signal and found that there was no change in the transient signal even after about 100 shots. One transient absorption trace was obtained by averaging 5-6 signals.

For spectral measurements, a system consisting of a $300-\mathrm{mm}$ monochromator (ACTON, SpectraPro 2358i) and a gated intensified charge-coupled device camera (Princeton Instruments, PI-MAX-II, UNIGENII) was used. The wavelength response of the detector was corrected by comparing the fluorescence spectrum of Coumarin 153 with a reported reference spectrum. ${ }^{46}$ The analyzing light after the sample cell was collimated to the optical bundle fiber and transferred to the spectrometer. A UV-cutoff filter $(420 \mathrm{~nm})$ was placed before the sample.

We also measured the transient fluorescence intensity of BPH with subnanosecond time resolution; we used the third harmonic $(355 \mathrm{~nm})$ of an optical parametric oscillator (Spectra Physics, MOPO-SL) excited by a $\mathrm{Nd}^{3+}$ :YAG laser (Spectra Physics, Pro-230-10) to generate $\mathrm{BPH}$ and the second harmonic oscillation $(532 \mathrm{~nm})$ of a sub-nanosecond laser (EKSPLA, SL-311, $150 \mathrm{ps}$ ) to excite the BPH. The delay time between the two laser pulses was adjusted with a digital delay generator (Stanford Research Systems, DG535). Emission from BPH( $\left.D_{1}\right)$ was detected with a Si photodiode (New Focus, 1601) after being dispersed with a monochromator. The observed wavelength was $600 \mathrm{~nm}$. The signal from the detector was introduced into a digital oscilloscope (LeCroy, 6200A). The rise time of the overall system was about 400 ps.

\section{Results and Discussion}

Hydrogen abstraction by $\mathrm{BP}$ in the triplet excited state, $\mathrm{BP}\left(\mathrm{T}_{1}\right)$, is known to generate $\mathrm{BPH}$ in organic solvents such as cyclohexane, toluene, and alcohols. However, studies of the reaction of $\mathrm{BP}\left(\mathrm{T}_{1}\right)$ in ILs are limited. ${ }^{18,19,38}$ In TMPA-TFSA, the lifetime of $\mathrm{BP}\left(\mathrm{T}_{1}\right)$ is reported to be $19 \mu \mathrm{s}$, which is substantially longer than the lifetimes in cyclohexane (300 ns), 2-propanol (5 ns), and

benzene $(3 \mu \mathrm{s}) .{ }^{19}$ In contrast, the lifetime of $\mathrm{BP}\left(\mathrm{T}_{1}\right)$ in Bmim-TFSA has been reported to be $3 \mu \mathrm{s}$. These results suggest that TMPA-TFSA is unreactive with $\mathrm{BP}\left(\mathrm{T}_{1}\right)$ and that Bmim-TFSA is substantially more reactive with $\mathrm{BP}\left(\mathrm{T}_{1}\right)$ than TMPA-TFSA. It has been suggested that $\mathrm{BP}\left(\mathrm{T}_{1}\right)$ 
abstracts a hydrogen atom from the 2-position of the imidazolium ring of Bmim-TFSA. ${ }^{18}$

In Fig. 2, transient absorption spectra after the excitation of BP with a 355-nm pulse in (a) TMPA-TFSA and in (b) Bmim-TFSA are shown. Comparison of these two spectra with previously reported spectra in methanol and acetonitrile ${ }^{17,42-44}$ clearly indicates that the spectra observed in TMPA-TFSA until $10 \mu$ s after the pulse can be attributed to $\mathrm{BP}\left(\mathrm{T}_{1}\right)$; in contrast, the spectra observed in Bmim-TFSA at $4 \mu$ s after the pulse clearly indicate the formation of BPH. The spectra in Bmim-TFSA are consistent with the spectrum recently measured in Bmim- $\mathrm{PF}_{6}$ by Nishiyama et al. ${ }^{38}$ Therefore, as previously suggested, ${ }^{18,19}$ hydrogen abstraction is slow in TMPA-TFSA.

Because BPH was produced in Bmim-TFSA, we examined BPH in the $\mathrm{D}_{1}$ excited state generated with a 532-nm laser pulse in Bmim-TFSA. Upon excitation with the 532-nm pulse, BPH emitted fluorescence from the $\mathrm{D}_{1}$ state (Fig. 2b). The fluorescence spectrum was measured $20 \mu$ s after the 355-nm pulse with a 3-ns gate width and was fitted by a log-normal function. The peak of the spectrum was $594 \mathrm{~nm}$. Because the absorption maximum was located around $539.5 \mathrm{~nm}$, the Stokes shift, $v_{\text {Stokes }}$, of BPH in Bmim-TFSA was determined to be 1700 $\mathrm{cm}^{-1}$. The present results are compared with previously reported results in several organic solvents in Table 1; the absorption maximum in the visible region $\lambda_{\mathrm{Abs}}^{\max }$, the fluorescence maximum $\lambda_{\text {Fluo }}^{\max }, v_{\text {Stokes }}$, the energy gap between the fully equilibrated $\mathrm{D}_{1}$ and $\mathrm{D}_{0}$ states of $\mathrm{BPH}$ $\Delta E\left(D_{1}-D_{0}\right)$, and the fluorescence lifetimes $\tau_{\mathrm{f}}$ of $\mathrm{BPH}\left(\mathrm{D}_{1}\right)$ are listed in the table. It has been reported $^{43}$ that the relationship between the Dimroth $E_{\mathrm{T}}(30)$ parameter ${ }^{49}$ and $v_{\text {Stokes }}$ is linear in organic solvents except for 2-propanol and methanol, as shown in Fig. 3. The line in Fig. 3 shows the correlation between $v_{\text {Stokes }}$ and $E_{\mathrm{T}}(30)$ with the alcohol data excluded. Because $v_{\text {Stokes }}$ of BPH was measured to be $1700 \mathrm{~cm}^{-1}$ in Bmim-TFSA, $E_{\mathrm{T}}(30)$ for Bmim-TFSA was determined to be $45.3 \mathrm{kcal} / \mathrm{mol}$ from the correlation. This value is close to the value for acetonitrile. In contrast, it has been reported that $E_{\mathrm{T}}(30)$ for Bmim-TFSA is $50-52 \mathrm{kcal} / \mathrm{mol}{ }^{50}$ When we used $52 \mathrm{kcal} / \mathrm{mol}$ as $E_{\mathrm{T}}(30), v_{\text {Stokes }}$ of BPH was calculated to be $2084 \mathrm{~cm}^{-1}$, which represents a $384 \mathrm{~cm}^{-1}$ difference from the measured value.

One possible reason for the difference in $v_{\text {Stokes }}$ may be a blue shift of the fluorescence spectra if the solvation dynamics of Bmim-TFSA around the excited BPH( $\left(\mathrm{D}_{1}\right)$ are slow compared to the excited-state lifetime of $\mathrm{BPH}\left(\mathrm{D}_{1}\right) .{ }^{51-58}$ The dipole moment of $\mathrm{BPH}\left(\mathrm{D}_{0}\right)$ is estimated to be $1.71 \mathrm{D}$, whereas the dipole moment of $\mathrm{BPH}\left(\mathrm{D}_{1}\right)$ is estimated to be $7.0 \mathrm{D} .{ }^{43}$ The 
large dipole moment of $\mathrm{BPH}\left(\mathrm{D}_{1}\right)$ suggests that $\mathrm{BPH}\left(\mathrm{D}_{1}\right)$ is highly polarized in the excited state. Therefore a relatively large change in solvation structure may be required after the excitation of $\operatorname{BPH}\left(\mathrm{D}_{0}\right)$. However, if the solvation dynamics of Bmim-TFSA are not fast enough to form a stable solvation structure during the lifetime of $\mathrm{BPH}\left(\mathrm{D}_{1}\right)$, a blue shift of the fluorescence spectra of $\mathrm{BPH}\left(\mathrm{D}_{1}\right)$ may result. The solvation time for Bmim-TFSA obtained by means of a $\mathrm{C} 153$ probe is reported to be $0.28 \mathrm{~ns}$ at $298 \mathrm{~K} \cdot{ }^{59,60}$ If the fluorescence lifetime of $\mathrm{BPH}\left(\mathrm{D}_{1}\right)$ in Bmim-TFSA is comparable to or shorter than the solvation time, slow solvent relaxation may explain the difference between the measured and estimated $v_{\text {Stokes }}$ values. To evaluate this possibility, we measured the fluorescence lifetime of $\mathrm{BPH}\left(\mathrm{D}_{1}\right)$ using the two-laser synchronized system. BPH( $\left(\mathrm{D}_{0}\right)$ was formed by irradiation of BP with a nanosecond laser pulse $(355 \mathrm{~nm})$, and then a picosecond laser pulse $(532 \mathrm{~nm})$ was used to excite the $\operatorname{BPH}\left(\mathrm{D}_{0}\right)$. The fluorescence signal from $\operatorname{BPH}\left(\mathrm{D}_{1}\right)$ in Bmim-TFSA is shown in Fig. 4. The lifetime in Bmim-TFSA was found to be $5.0 \pm 0.04 \mathrm{~ns}$, which is the same as the lifetime in acetonitrile (Table 1, entries 6 and 7). These results indicate that the fluorescence lifetime of $\operatorname{BPH}\left(\mathrm{D}_{1}\right)$ in Bmim-TFSA was too long to support the above-mentioned hypothesis.

Another possible reason for the difference in the $v_{\text {Stokes }}$ values may be a specific interaction of Bmim-TFSA, especially the 2-position of the imidazolium ring, with the zwitterionic betaine dye used as the probe molecule for the measurement of $E_{\mathrm{T}}(30)$; the $\mathrm{H}$ atom at the 2-position of imidazolium is known to participate in hydrogen bonding. ${ }^{61}$ As can be seen in Fig. 3, the $v_{\text {Stokes }}$ values in hydrogen-bonding solvents, such as 2-propanol and methanol, deviated from the relationship observed for other organic solvents. It has been suggested that 1-methyl-3-alkylimidazolium cations can act as weak hydrogen-bond donors because of the weakly acidic $\mathrm{C}(2)-\mathrm{H}$ hydrogen atom on the heterocyclic ring. Replacement of the $\mathrm{C}(2)-\mathrm{H}$ atom with an alkyl group results in a substantial decrease in $E_{\mathrm{T}}(30) .{ }^{62}$ For example, $E_{\mathrm{T}}(30)$ for 1,2-dimethyl-3-butylimidazolium-TFSA is $48.6 \mathrm{kcal} / \mathrm{mol}$, which is close to the estimated value in the present study. Recently, Kawai et al. studied the solvation of BPH in ILs by evaluating the hyperfine coupling constant of the hydroxyl proton by means of time-resolved electron paramagnetic resonance measurements. ${ }^{63}$ The hyperfine coupling constant of the hydroxyl proton depends on Gutmann's donor number of the anions, whereas the constants of phenyl $\alpha$-protons are essentially the same for these ILs. Kawai et al. speculated that the electron-donating character of the anions is important in the solvation in ILs through the anion-OH group. The relatively long fluorescence lifetime of $\operatorname{BPH}\left(\mathrm{D}_{1}\right)$ in $\operatorname{Bmim-TFSA}$ 
suggests that the interaction between $\mathrm{BPH}\left(\mathrm{D}_{1}\right)$ and Bmim-TFSA was weak. The fluorescence lifetime in methanol, in which hydrogen bonding may be important, was much shorter than that in other, non-hydrogen-bonding solvents. The strong interaction between $\mathrm{BPH}\left(\mathrm{D}_{1}\right)$ and solvent may have increased nonradiative relaxation, which shortened the fluorescence lifetime. Because the fluorescence lifetime in Bmim-TFSA was the same as that in acetonitrile, the interaction of $\mathrm{BPH}\left(\mathrm{D}_{1}\right)$ with Bmim-TFSA may have been similar to that with acetonitrile, as previously suggested by non-equilibrium molecular dynamics simulations. ${ }^{64}$

The transient kinetics of the excited state of BPH were examined in methanol and Bmim-TFSA (Fig. 5a, b). The transient signals were monitored at $500 \mathrm{~nm}$, and $\mathrm{CCl}_{4}$ was added as a reaction partner for the excited state of $\mathrm{BPH}$. $\mathrm{BPH}\left(\mathrm{D}_{0}\right)$ formed by excitation with a $355-\mathrm{nm}$ pulse was excited with a 532-nm pulse at $1 \mu$ s (in methanol) or $20 \mu$ s (in Bmim-TFSA) after the 355-nm pulse. When the sample containing $\mathrm{CCl}_{4}$ was irradiated with the 532-nm laser pulse, the transient absorption signal displayed an instrument-limited decrease, and the decrease of absorption did not recover within the lifetime of $\mathrm{BPH}\left(\mathrm{D}_{0}\right)$. As the concentration of $\mathrm{CCl}_{4}$ was increased, the amount of the permanent bleaching increased. Therefore the bleaching can be attributed to the reaction of $\mathrm{BPH}\left(\mathrm{D}_{1}\right)$ with $\mathrm{CCl}_{4}$. $\mathrm{BPH}\left(\mathrm{D}_{1}\right)$ reportedly decays through radiative and nonradiative relaxations and through unimolecular and bimolecular chemical reaction processes. ${ }^{41-44}$ Reported unimolecular chemical reaction processes include $\mathrm{O}-\mathrm{H}$ bond cleavage and photoionization of $\operatorname{BPH}\left(\mathrm{D}_{1}\right)$. After the photoionization, a solvated electron may be formed. For the bimolecular reaction of $\mathrm{BPH}\left(\mathrm{D}_{1}\right)$, an electron transfer reaction from $\mathrm{BPH}\left(\mathrm{D}_{1}\right)$ to $\mathrm{BP}$ has been suggested. ${ }^{44}$ After considering these reaction paths, we propose the following reactions to explain the permanent bleaching that we observed:

$$
\begin{aligned}
& \mathrm{BPH}\left(\mathrm{D}_{1}\right) \stackrel{k_{1}}{\longrightarrow} \mathrm{BPH}\left(\mathrm{D}_{0}\right) \\
& \mathrm{BPH}\left(\mathrm{D}_{1}\right) \stackrel{k_{2}}{\longrightarrow} \mathrm{BP}+\mathrm{H}, \text { or } \mathrm{BPH}^{+}+e_{s} \\
& \mathrm{BPH}\left(\mathrm{D}_{1}\right)+\mathrm{BP} \stackrel{k_{3}}{\longrightarrow} \mathrm{BPH}^{+}+\mathrm{BP}^{-} \\
& \mathrm{BPH}\left(\mathrm{D}_{1}\right)+\mathrm{CCl}_{4} \stackrel{k_{4}}{\longrightarrow} \mathrm{P}
\end{aligned}
$$

where $k_{1}, k_{2}, k_{3}$, and $k_{4}$ are the rate constants for the respective reactions. Though we cannot yet specify the product $\mathrm{P}$ obtained from reaction $\mathrm{R} 4$, an electron-transfer reaction from $\mathrm{BPH}\left(\mathrm{D}_{1}\right)$ to $\mathrm{CCl}_{4}$ is one possibility. Because reaction $\mathrm{R} 1$ re-produces $\mathrm{BPH}\left(\mathrm{D}_{0}\right)$ after the excitation of $\operatorname{BPH}\left(\mathrm{D}_{0}\right)$, this reaction cannot contribute to the bleaching of $\mathrm{BPH}\left(\mathrm{D}_{0}\right)$. In contrast, because reactions $\mathrm{R} 2, \mathrm{R} 3$, and $\mathrm{R} 4$ do not re-produce $\mathrm{BPH}\left(\mathrm{D}_{0}\right)$, these reaction result in signal bleaching. Therefore, the following relationship between the observed bleaching and the above reactions 
can be established:

$$
\frac{\left(\mathrm{Abs}_{0}-\mathrm{Abs}_{\mathrm{t}}\right)}{F \times \mathrm{Abs}_{0}}=\frac{k_{2}\left[\mathrm{BPH}\left(\mathrm{D}_{1}\right)\right]+k_{3}\left[\mathrm{BPH}\left(\mathrm{D}_{1}\right)\right][\mathrm{BP}]+k_{4}\left[\mathrm{BPH}\left(\mathrm{D}_{1}\right)\right]\left[\mathrm{CCl}_{4}\right]}{k_{1}\left[\mathrm{BPH}\left(\mathrm{D}_{1}\right)\right]+k_{2}\left[\mathrm{BPH}\left(\mathrm{D}_{1}\right)\right]+k_{3}\left[\mathrm{BPH}\left(\mathrm{D}_{1}\right)\right][\mathrm{BP}]+k_{4}\left[\mathrm{BPH}\left(\mathrm{D}_{1}\right)\right]\left[\mathrm{CCl}_{4}\right]}
$$

where $\mathrm{Abs}_{0}$ and $\mathrm{Abs}_{t}$ are the absorbances immediately before and after the 532-nm pulse, respectively, and $F$ is a constant that depends on experimental conditions such as laser intensity and quantum efficiency for the formation of $\mathrm{BPH}\left(\mathrm{D}_{1}\right)$ upon 532-nm irradiation of $\mathrm{BPH}\left(\mathrm{D}_{0}\right)$. Though fitting the bleaching amount using $k_{1}-k_{4}$ and $F$ may be possible, we improved the fitting reliability by determining $F$ by means of the following method. When the concentration of $\mathrm{CCl}_{4}$ is high enough that $k_{4}\left[\mathrm{CCl}_{4}\right]>\left(k_{2}+k_{3}[\mathrm{BP}]\right)$, eqn (1) can be written as

$$
\frac{\mathrm{Abs}_{0}}{\mathrm{Abs}_{0}-\mathrm{Abs}_{t}}=\frac{1}{F}+\frac{k_{1}}{F \times k_{4}\left[\mathrm{CCl}_{4}\right]}
$$

Therefore, at high $\mathrm{CCl}_{4}$ concentrations, $F$ and $k_{1} / k_{4}$ can be determined from a plot of $\mathrm{Abs}_{0} /\left(\mathrm{Abs}_{0}\right.$ $-\mathrm{Abs}_{t}$ ) versus $1 /\left[\mathrm{CCl}_{4}\right]$. The relationship between these two quantities was linear at high $\mathrm{CCl}_{4}$ concentrations, and the $F$ values in methanol and Bmim-TFSA were determined to be $0.71 \pm$ 0.06 and $0.72 \pm 0.08$, respectively.

Eqn (1) can be rewritten as

$$
\frac{\mathrm{Abs}_{0}}{\mathrm{Abs}_{0}-\mathrm{Abs}_{t}}=\frac{1}{F}\left[\frac{k_{1} / k_{4}}{\left(k_{2}+k_{3}[\mathrm{BP}]\right) / k_{4}+\left[\mathrm{CCl}_{4}\right]}+1\right]
$$

Using the $F$ values determined above, $k_{1} / k_{4}$ and $\left(k_{2}+k_{3}[\mathrm{BP}]\right) / k_{4}$ were determined by least-squares fitting of the data (Fig. 6, Table 2); the $k_{1} / k_{4}$ values were determined to be $(7.9 \pm$ $0.9) \times 10^{-2} \mathrm{M}$ in methanol and $(9.4 \pm 1.6) \times 10^{-2} \mathrm{M}$ in Bmim-TFSA. Because the $k_{1}$ values were estimated to be $4 \times 10^{9}$ and $2 \times 10^{8} \mathrm{~s}^{-1}$ from the lifetimes of $\operatorname{BPH}\left(\mathrm{D}_{1}\right)$ in methanol and Bmim-TFSA, respectively, the $k_{4}$ vales in methanol and Bmim-TFSA were determined to be $(5.1 \pm 0.6) \times 10^{10}$ and $(2.1 \pm 0.4) \times 10^{9} \mathrm{M}^{-1} \mathrm{~s}^{-1}$, respectively. These values suggest that the reaction of $\mathrm{BPH}\left(\mathrm{D}_{1}\right)$ with $\mathrm{CCl}_{4}$ was diffusion limited. The diffusion-limited rate constant $k_{\text {diff }}$ based on the hydrodynamic approximation (the Stokes-Einstein equation) is given by ${ }^{30-35}$

$$
k_{\text {diff }}=8000 R T / 3 \eta
$$

where $\eta$ is viscosity (in Pa s), and $R$ is the gas constant $\left(8.314 \mathrm{~J} \mathrm{~K}^{-1} \mathrm{~mol}^{-1}\right)$. Using the viscosity of Bmim-TFSA, we calculated the reaction rate to be $1.2 \times 10^{8} \mathrm{M}^{-1} \mathrm{~s}^{-1}$, which is $1 / 10$ the measured rate constant. A limitation on using the Stokes-Einstein equation for estimating diffusion-limited reaction rates has been discussed previously. For example, McLean et al. studied the quenching of the triplet state of BP by naphthalene in imidazolium-based ILs ${ }^{9}$ and 
found that the reaction rates were nearly 10 times the rates predicted by eqn (4). This result suggests that the diffusion coefficient we calculated from the bulk viscosity of ILs was not necessarily correct.

An alternative way to estimate the diffusion-limited rate constant is to calculate it with the Smoluchowski equation: ${ }^{39}$

$$
k_{\mathrm{diff}}=4 \pi \mathrm{D}_{\mathrm{AB}} r_{\mathrm{AB}}
$$

where $D_{\mathrm{AB}}$ is a mutual diffusion coefficient for the reactants, and $r_{\mathrm{AB}}$ is the reaction distance. The diffusion coefficient of $\mathrm{BPH}\left(\mathrm{D}_{0}\right)$ in Bmim-TFSA has been determined previously by a transient grating method, ${ }^{38,39}$ but there is no value for $\mathrm{BPH}\left(\mathrm{D}_{1}\right)$. When we assumed $D_{\mathrm{AB}}$ to be twice the diffusion coefficient of $\mathrm{BPH}\left(\mathrm{D}_{0}\right)$, and the reaction distance to be sum of van der Waals radii of $\mathrm{BPH}\left(\mathrm{D}_{0}\right)(0.4 \mathrm{~nm})^{38,39}$ and $\mathrm{CCl}_{4}(0.17 \mathrm{~nm}),{ }^{65}$ the calculated diffusion-limited rate constant was $1.1 \times 10^{8} \mathrm{M}^{-1} \mathrm{~s}^{-1}$. This value is still far from the measured rate constant. Therefore our assumption about $D_{\mathrm{AB}}$ was not adequate for estimating the reaction rate of $\mathrm{BPH}\left(\mathrm{D}_{1}\right)$ with $\mathrm{CCl}_{4}$ in Bmim-TFSA. To estimate the reaction rate using eqn (5), we would have to have the actual diffusion coefficients of $\mathrm{BPH}\left(\mathrm{D}_{1}\right)$ and $\mathrm{CCl}_{4}$ in Bmim-TFSA. In general, the translational diffusion of a small molecule in ILs is known to be much faster than predicted by the Stokes-Einstein equation. For example, the diffusion coefficients of CO measured in ILs are 10 to 50 times the values predicted by the viscosity of ILs. ${ }^{38}$ In addition, the diffusion coefficient of $\mathrm{BPH}\left(\mathrm{D}_{0}\right)$ is reported to be exceptionally slow ${ }^{38}$ and is close to the value predicted by the Stokes-Einstein equation. Therefore, as the molecular size of $\mathrm{CCl}_{4}$ is small, the diffusion coefficient of $\mathrm{CCl}_{4}$ in $\mathrm{Bmim}$-TFSA can be expected to be much faster than the values predicted by the Stokes-Einstein equation.

Recently Wakasa ${ }^{19}$ suggested that a cage effect may be more important than viscosity in explaining the large magnetic field effects (MFE) on abstraction of a hydrogen atom from thiophenol by BP in ILs. If there is local structure in ILs, as there is in micellar solutions, the large MFE can be explained by the cage effect. The presence of local structure or domains in ILs has been previously reported. ${ }^{20-27,66-68}$ Wakasa et al. recently reported that the sphere cage model well reproduces the observed MFE. ${ }^{69}$ A nanoscale heterogeneous structure with a cage radius of $1.8 \mathrm{~nm}$ and an effective viscosity in the cage of 1-2 $\mathrm{mPa}$ s has been found. Using an effective viscosity of $2 \mathrm{mPa}$, we calculated a diffusion-limited rate constant of $3 \times 10^{9} \mathrm{M}^{-1} \mathrm{~s}^{-1}$ from eqn (4). This value is close to the rate constant measured in the present study. Therefore the reaction rate of $\mathrm{BPH}\left(\mathrm{D}_{1}\right)$ with $\mathrm{CCl}_{4}$ in $\mathrm{Bmim}$-TFSA may be explained by considering the 
effective microscopic viscosity.

The value of $k_{4}$ is 100 times $\left(k_{2}+k_{3}[\mathrm{BP}]\right)$ in Bmim-TFSA, and $\left(k_{2}+k_{3}[\mathrm{BP}]\right)$ in Bmim-TFSA is $1 / 10$ that in methanol (Table 2). Therefore the contribution of reaction paths for the dissociation and ionization of $\mathrm{BPH}\left(\mathrm{D}_{1}\right)$ may be minor compared to the contributions of the reaction of $\mathrm{BPH}\left(\mathrm{D}_{1}\right)$ with $\mathrm{CCl}_{4}$ and the relaxation to the ground state in Bmim-TFSA. In contrast, the photo-excitation of BPH in polar solvents is known to lead to the formation of solvated electrons. ${ }^{43-44}$ In the present study we found no experimental evidence for the formation of solvated electrons in Bmim-TFSA. Even if an electron had been ejected from BPH, the electron would have immediately been scavenged by the Bmim cation, as we previously reported. ${ }^{36,70}$ Therefore, the contribution of solvated electrons in the present reaction system was probably negligible. However, the ejection of an electron from the excited BPH into ILs is an interesting possibility. We previously examined photo-excitation of solvated electrons in TMPA-TFSA. ${ }^{71}$ After the photo-excitation of the solvated electrons at 532-nm, we observed permanent bleaching of the solvated electrons. The permanent photo-bleaching may have been due to formation of quasi-free electrons, which are highly mobile in the IL. We are planning to study the present reaction system in ILs in which solvated electrons are stable.

\section{Conclusion}

Two-color dual-pulse (355- and 532-nm) laser flash photolysis was used to study the $\mathrm{D}_{1}$ excited state of benzophenone ketyl radical, $\mathrm{BPH}\left(\mathrm{D}_{1}\right)$. The transient absorption spectra of the ketyl radical and the fluorescence spectrum of $\mathrm{BPH}\left(\mathrm{D}_{1}\right)$ were measured in Bmim-TFSA. The Stokes shift in Bmim-TFSA was $1700 \mathrm{~cm}^{-1}$, and this value was close to that in acetonitrile despite the fact that the dielectric constant of Bmim-TFSA (11.52) is substantially smaller than that of acetonitrile (36). This result suggests importance of local heterogeneous structure in Bmim-TFSA. Local heterogeneous structure results from structurally distinct domains of polarity and nonpolarity occupied by the charged and uncharged parts of the constituent ions, respectively, and BPH may be localized around the polar domain rather than the nonpolar domain.

The reaction of $\operatorname{BPH}\left(\mathrm{D}_{1}\right)$ was examined for the first time in IL Bmim-TFSA by means of two-color dual-pulse laser flash photolysis. The fluorescence lifetime of $\mathrm{BPH}\left(\mathrm{D}_{1}\right)$ in Bmim-TFSA was determined to be $5 \mathrm{~ns}$. After excitation of the ketyl radical with 532-nm light, permanent bleaching due to the reaction with $\mathrm{CCl}_{4}$ was observed. The rate of the reaction of 
$\mathrm{BPH}\left(\mathrm{D}_{1}\right)$ with $\mathrm{CCl}_{4}$ was 10 times that expected from the hydrodynamic approximation. In contrast, the measured rate constant in Bmim-TFSA was well reproduced when the effective viscosity in a nanoscale heterogeneous structure was considered. This result confirms the importance of local heterogeneous structure in Bmim-TFSA in chemical reactions.

Through the present work, we felt that a new type of experiment for evaluating the excitation-wavelength dependence of electron-transfer reactions may provide interesting information about ILs. As pointed out by Annapureddy and Margulas, ${ }^{54}$ if the lifetime of an excited state is shorter than the time required for solvent relaxation, the electron-transfer rate may depend on the excitation wavelength. These investigators suggested that ILs provide a tool for manipulating the outcome of chemical reactions simply by tuning the initial excitation wavelength, and that ILs offer an extra degree of control of chemical reactivity. We believe that excited-state BPH may be a good candidate for testing their suggestion, and we are now planning to carry out this experiment at low temperature to make solvation slower than the lifetime of the excited state.

\section{Acknowledgments}

The authors thank J. F. Wishart (BNL) for stimulating discussions. We acknowledge the Ministry of Education, Culture, Sports, Science and Technology (MEXT) of Japan for a Grant-in-Aid for Scientific Research (Priority Area 452 "Science of Ionic Liquids"). 


\section{References}

1 N. V. Plechkova and K. R. Seddon, Chem. Soc. Rev., 2008, 37, 123-150.

2 V. I. Pàrvulescu and C. Hardacre, Chem. Rev., 2007, 107, 2615-2665.

3 T. Welton, Coord. Chem. Rev., 2004, 248, 2459-2477.

4 D. R. Macfarlane, M. Forsyth, P. C. Howlett, J. M. Pringle, J. Sun, G. Annat, W. Neil and E. I. Izgorodina, Accounts Chem. Res., 2007, 40, 1165-1173.

5 P. Wasserscheid and W. Kein, Angew. Chem., Int. Ed., 2000, 39, 3772-3789.

6 J. Dupont, R. F. de Souza and P. A. Z. Suarez, Chem. Rev., 2002, 102, 3667-3692.

7 G. Hondrogiannis, C. W. Lee, R. Pagni and G. Mamantov, J. Am. Chem. Soc., 1993, 115, 9828-9829.

8 C. W. Lee, T. Winston, A. Unni, R. M. Pagni and G. Mamantov, J. Am. Chem. Soc., 1996, 118, 4919-4924.

9 C. M. Gordon and A. J. McLean, Chem. Commun., 2000, 1395-1396.

10 R. Ozawa and H. Hamaguchi, Chem. Lett., 2001, 30, 736-737.

11 M. Álvaro, B. Ferrer and H. García, Chem. Phys. Lett., 2002, 362, 435-440.

12 R. Karmakar and A. Samanta, Chem. Phys. Lett., 2003, 376, 638-645.

13 B. Bhattacharya and A. Samanta, J. Phys. Chem. B, 2008, 112, 10101-10106.

14 A. Paul and A. Samanta, J. Phys. Chem. B, 2007, 111, 1957-1962.

15 R. C. Vieira and D. E. Falvey, J. Phys. Chem. B, 2007, 111, 5023-5029.

16 R. C. Vieira and D. E. Falvey, J. Ame. Chem. Soc., 2008, 130, 1552-1553.

17 G. Porter and F. Wilkinston, Trans. Faraday Soc., 1961, 57, 1686-1691.

18 M. J. Muldoon, A. J. McLean, C. M. Gordon and I. R. Dunkin, Chem. Commun., 2001, 2364-2645.

19 M. Wakasa, J. Phys. Chem B, 2007, 111, 9434-9436.

20 S. Hayashi, R. Ozawa and H. Hamaguchi, Chem. Lett., 2003, 32, 498-499.

21 R. Ozawa, S. Hayashi, S. Saha, A. Kobayashi and H. Hamaguchi, Chem. Lett. 2003, 32, 948-949.

22 S. Shigeto, H. Hamaguchi, Chem Phys. Lett. 2006, 427, 329-332.

23 K. Iwata, K. Yoshida, Y. Takada and H. Hamaguchi, Chem. Lett. 2007, 36, 504-505.

24 K. Iwata, H. Okajima, S. Saha and H. Hamaguchi, Acc. Chem. Res., 2007, 40, 1174-1181.

25 A. Triolo, O. Russina, H. J. Bleif and E. Di Cola, J. Phys. Chem. B, 2007, 111, 4641-4644.

26 M. G. Del Popolo and G. A. Voth, J. Phys. Chem. B, 2004, 108, 1744-1752. 
27 Y. T. Wang and G.A. Voth, J. Am. Chem. Soc., 2005, 127, 12192-12193.

28 H. Weingartner, Angew. Chem. Int. Ed. 2008, 47, 654-670.

29 T. Kondoh, A. Asano, J. Yang, K. Norizawa, K. Takahashi, M. Taguchi, R. Nagaishi, R.

Katoh, Y. Yoshida, Rad. Phys. Chem., 2009, 78, 1157-1160

30 D. Behar, C. Gonzalez and P. Neta, J. Phys. Chem. A, 2001, 105, 7607-7614.

31 J. Grodkowski and P. Neta, J. Phys. Chem. A, 2002, 106, 5468-5473.

32 J. Grodkowski and P. Neta, J. Phys. Chem. A, 2002, 106, 9030-9035.

33 J. Grodkowsk and P. Neta, J. Phys. Chem. A, 2002, 106, 11130-11134.

34 J. F. Wishart and P. Neta, J. Phys. Chem. B, 2003, 107, 7261-7267.

35 J. Grodkowski, P. Neta and J. F. Wishart, J. Phys. Chem. A, 2003, 107, 9794-9799.

36 R. Katoh, Y. Yoshida,Y. Katsumura and K. Takahashi, J. Phys. Chem. B, 2007, 111, 4770-4774.

37 K. Takahashi, S. Sakai, H. Tezuka, Y. Hiejima, Y. Katsumura and M. Watanabe, J. Phys. Chem. B, 2007, 111, 4807-4811.

38 Y. Nishiyama, M. Fukuda, M. Terazima and Y. Kimura, J. Chem. Phys., 2008, 128, 164514.

39 Y. Nishiyama, M. Terazima and Y. Kimura, J. Phys. Chem. B, 2009, 113, 5188-5193.

40 V. Nagarajan and R. W. Fessenden, Chem. Phys. Lett., 1984, 112, 207-211.

41 R.W. Redmond, J. C. Scaiano and L. J. Johnston, J. Ame. Chem. Soc., 1992, 114, 9768-9773.

42 M. Sakamoto, X. Cai, M. Hara, S. Tojyo, M. Fujitsuka and T. Majima, J. Phys. Chem. A, 2004, 108, 8147-8150.

43 M. Sakamoto, X. Cai, M. Fujitsuka and T. Majima, J. Phys. Chem. A, 2006, 110, 11800-11808.

44 M. Sakamoto, X. Cai, S. S. Kim, M. Fujitsuka and T. Majima, J. Phys. Chem. A, 2007, 111, 223-229.

45 R. Katoh and K. Takahashi, Rad. Phys. Chem., 2009, 78, 1126-1128

46 J. A. Gardecki and M. Maroncelli, Appl. Spectrosc., 1998, 52, 1179-1189.

47 H. Weingartner, P. Sasisanker, C. Daguenet, P. J. Dyson, I. Krossing, J. M. Slattery and T. Schubert, J. Phys. Chem. B, 2007, 111, 4775-4780.

48 C. Wakai, A. Oleinikova, M. Ott and H. Weingartner, J. Phys. Chem. B, 2005, 109, 17028-17030.

49 C. Reichardt, Chem. Rev., 1994, 94, 2319-2358.

50 M. J. Muldon, C. M. Gordon and I. R. Dunkin, J. Chem. Soc., Perkin Trans.2, 2001, 
433-435.

51 P. K. Mandal, M. Sarkar and A. Samanta, J. Phys. Chem. A, 2004, 108, 9048-9053.

52 A. Samanta, J. Phys. Chem. B, 2006, 110, 13704-13716.

53 Z. Hu and C. J. Margulis, J. Phys. Chem. B, 2006, 110, 11025-11028.

54 H. Jin, X. Li and M. Maroncelli, J. Phys. Chem. B, 2007, 111, 13473-13478.

55 H. V. R. Annapureddy and C. J. Margulis, J. Phys. Chem. B, 2009, 113, 12005-12012.

56 Y. Shim and H. Kim, J. Phys. Chem. B, 2008, 112, 11028-11038.

57 D. Jeong, Y. Shim, M.Y. Choi and H. J. Kim, J. Phys. Chem. B, 2007, 111, 4920-4925.

58 Y. Shim and H. J. Kim, J. Phys. Chem. B, 2009, 113, DOI: 10.1021/jp9065407.

59 S. Arzhantsev, N. Ito, M. Heitz and M. Maroncelli, Chem. Phys. Lett., 2003, 381, 278-286.

60 H. Jin, G. A. Barker, S. Arzhantsev, J. Dong and M. Maroncelli, J. Phys. Chem. B, 2007, 111, 7291-7302.

61 K. Fumino, A. Wulf and R. Ludwig, Angew. Chem. Int. Ed., 2008, 47, 8731-8734.

62 C. Reichardt, Green Chem., 2005, 7, 339-351.

63 A. Kawai, T. Hidemori, and K. Shibuya, Chem. Phys. Lett., 2005, 414, 378-383.

64 Y. Shim and H. J. Kim, J. Chem. Phys., 2006, 125, 024507.

65 A. Bondi, J. Phys. Chem. 1964, 68, 441-451

66 H. Shirota, A.M. Funston, J.F. Wishart, E.W. Castner, Jr., J. Chem. Phys. 2005, 122, 84512

67 A. F. Funston, A.F. Fadeeva, J. F. Wishart and E. W. Castner, Jr., J. Phys. Chem. B, 2007, 111, 4963-4977.

68 J. N. C. Lopes and A. A. H. Padua, J. Phys. Chem. B, 2006, 110, 3330-3335.

69 M. Wakasa, T. Yago and A. Hamasaki, J. Phys. Chem. B, 2009, 113, 10559-10561.

70 K. Takahashi, T. Satoh, Y. Katsumura, J. Yang, T. Kondoh, Y. Yoshida and R. Katoh, Rad. Phys. Chem., 2008, 77, 1239-1243.

71 K. Takahashi, K. Suda, T. Seto, Y. Katsumura, R. Katoh, R. A. Crowell and J. F. Wishart, Rad. Phys. Chem., 2009, 78, 1129-1132. 
Table 1. Absorption and fluorescence maxima and Stokes shifts of BPH in several solvents

\begin{tabular}{|c|c|c|c|c|c|c|}
\hline Solvent & $\varepsilon$ & $\begin{array}{l}\lambda_{\mathrm{Abs}}^{\max } \\
(\mathrm{nm})\end{array}$ & $\begin{array}{l}\lambda_{\text {Fluo }}^{\max } \\
(\mathrm{nm})\end{array}$ & $\begin{array}{l}v_{\text {Stokes }} \\
\left(\mathrm{cm}^{-1}\right)\end{array}$ & $\begin{array}{l}\Delta E\left(D_{1}-D_{0}\right) \\
(\mathrm{eV})\end{array}$ & $\begin{array}{l}\tau_{\mathrm{f}} \\
(\mathrm{ns})\end{array}$ \\
\hline 1 cyclohexane & 2 & $541^{\mathrm{a}}$ & $564.9^{\mathrm{a}}$ & $780^{\mathrm{b}}$ & $2.20^{\mathrm{b}}$ & $2.0^{\mathrm{a}}$ \\
\hline 2 toluene & 2.4 & $540^{\mathrm{a}}$ & $571.6^{\mathrm{a}}$ & $1020^{b}$ & $2.17^{\mathrm{b}}$ & $2.8^{\mathrm{a}}$ \\
\hline $3 \mathrm{MTHF}$ & 7.6 & $548^{a}$ & $590.6^{\mathrm{a}}$ & $1320^{\mathrm{b}}$ & $2.10^{\mathrm{b}}$ & $1.8^{\mathrm{a}}$ \\
\hline 4 2-propanol & 20 & $547^{\mathrm{a}}$ & $595.6^{\mathrm{a}}$ & $1490^{b}$ & $2.08^{b}$ & $0.49^{\mathrm{a}}$ \\
\hline 5 methanol & 33 & $544^{\mathrm{a}}$ & $593.3^{\mathrm{a}}$ & $1530^{b}$ & $2.09^{b}$ & $0.26^{\mathrm{a}}$ \\
\hline 6 acetonitrile & 36 & $530^{\mathrm{a}}$ & $582.1^{\mathrm{a}}$ & $1688^{b}$ & $2.13^{b}$ & $4.7^{\mathrm{a}}$ \\
\hline 7 Bmim-TFSA & $11.52^{\mathrm{c}}$ & 540 & 594 & 1700 & 2.09 & $5.0 \pm 0.04^{\mathrm{d}}$ \\
\hline
\end{tabular}

${ }^{\mathrm{a}}$ Data from ref. 43, ambient temperature. ${ }^{\mathrm{b}}$ Calculated from $\lambda_{\mathrm{Abs}}^{\max }$ and $\lambda_{\text {Fluo }}^{\max }$ in this study. ${ }^{\mathrm{c}}$ Data from refs. 47 and $48 .{ }^{\text {d }}$ At $296 \mathrm{~K}$. 
Table 2. Fitting parameters in eqn (3).

\begin{tabular}{lllll}
\hline Solvent & $k_{1} / k_{4}(\mathrm{M})$ & $\left(k_{2}+k_{3}[\mathrm{BP}]\right) / k_{4}(\mathrm{M})$ & $F$ & $\eta(\mathrm{mPa} \mathrm{s})$ \\
\hline Methanol & $(7.9 \pm 0.9) \times 10^{-2}$ & $(7.4 \pm 0.5) \times 10^{-3}$ & $0.71 \pm 0.06$ & 0.56 \\
Bmim-TFSA & $(9.4 \pm 1.6) \times 10^{-2}$ & $(7.1 \pm 4.9) \times 10^{-4}$ & $0.72 \pm 0.08$ & 58
\end{tabular}


Figure Captions.

Fig. 1. Experimental set-up for two-color dual-pulse laser flash photolysis.

Fig. 2. Transient spectra of BP after 355-nm excitation in (a) TMPA-TFSA and (b) Bmim-TFSA. The spectra were taken at $1.7-\mu$ s intervals after the $355-\mathrm{nm}$ pulse. The fluorescence spectrum of $\mathrm{BPH}\left(\mathrm{D}_{1}\right)$ measured $10 \mu \mathrm{s}$ after the $355-\mathrm{nm}$ pulse is also shown in (b).

Fig. 3. Relationship between Stokes shift and $E_{\mathrm{T}}(30)$. The numbers in the figure correspond to the entry numbers in Table 1 . The solid line is the fit obtained using data for solvents 1 , 2,3 , and 6 only.

Fig. 4. Kinetic trace of fluorescence intensity of $\mathrm{BPH}\left(\mathrm{D}_{1}\right)$ monitored at $600 \mathrm{~nm}$ in Bmim-TFSA.

Fig. 5. Transient absorption signal monitored at $500 \mathrm{~nm}$ in (a) methanol and (b) Bmim-TFSA. After the 532-nm pulse irradiation, permanent bleaching was observed. The inset in (b) is a measurement with a high time resolution after 532-nm pulse irradiation.

Fig. 6. Relationship between normalized photo-bleaching and $\mathrm{CCl}_{4}$ concentration: $(\Delta)$ methanol, (•) Bmim-TFSA. Solid lines are fitting results for eqn (3). 


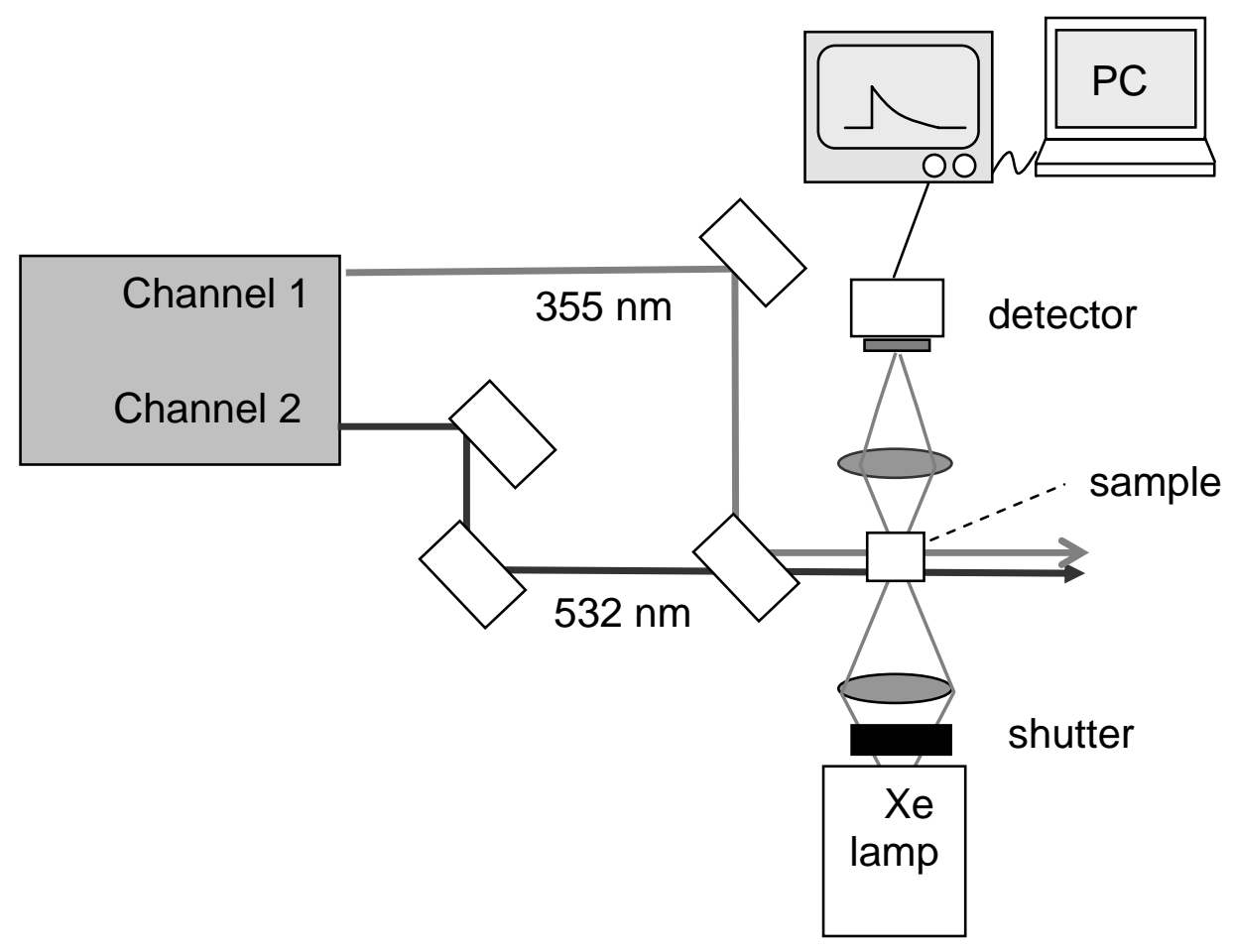

Fig. 1. 

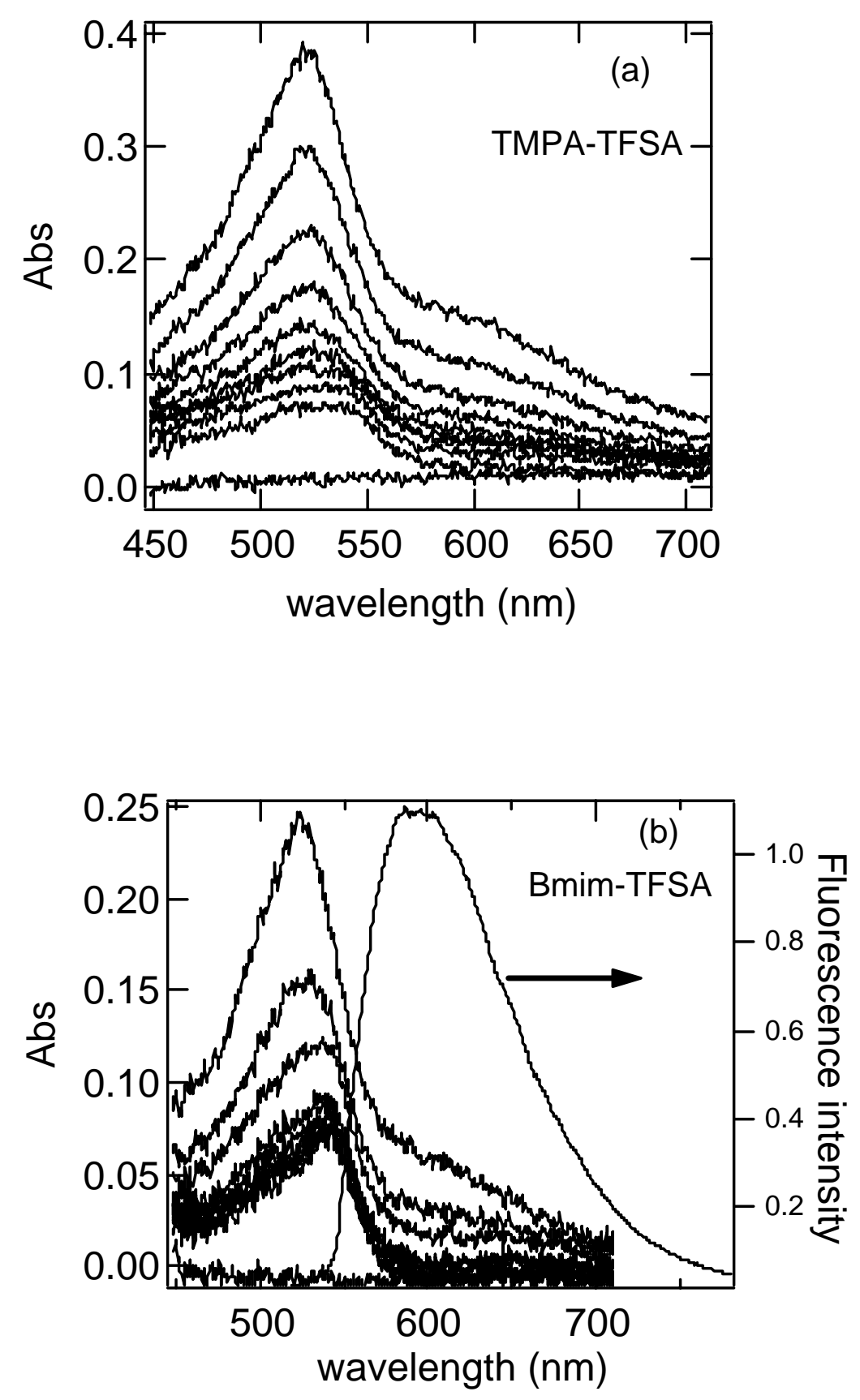

Fig. 2. 


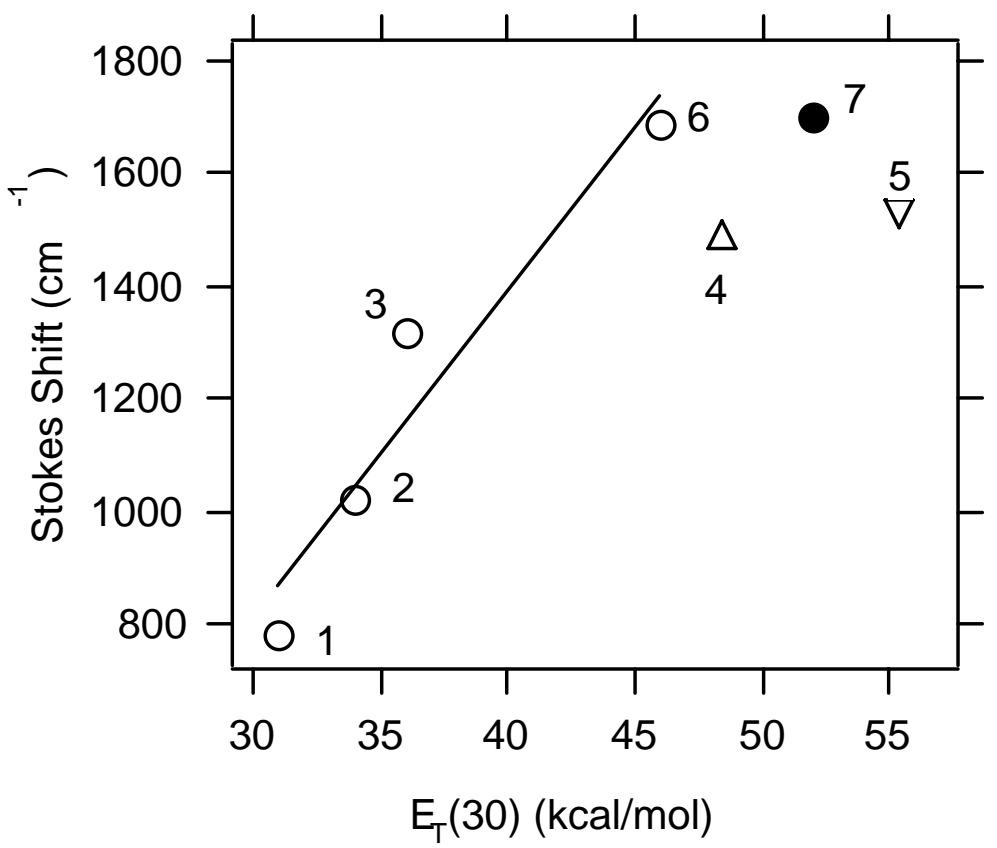

Fig. 3. 


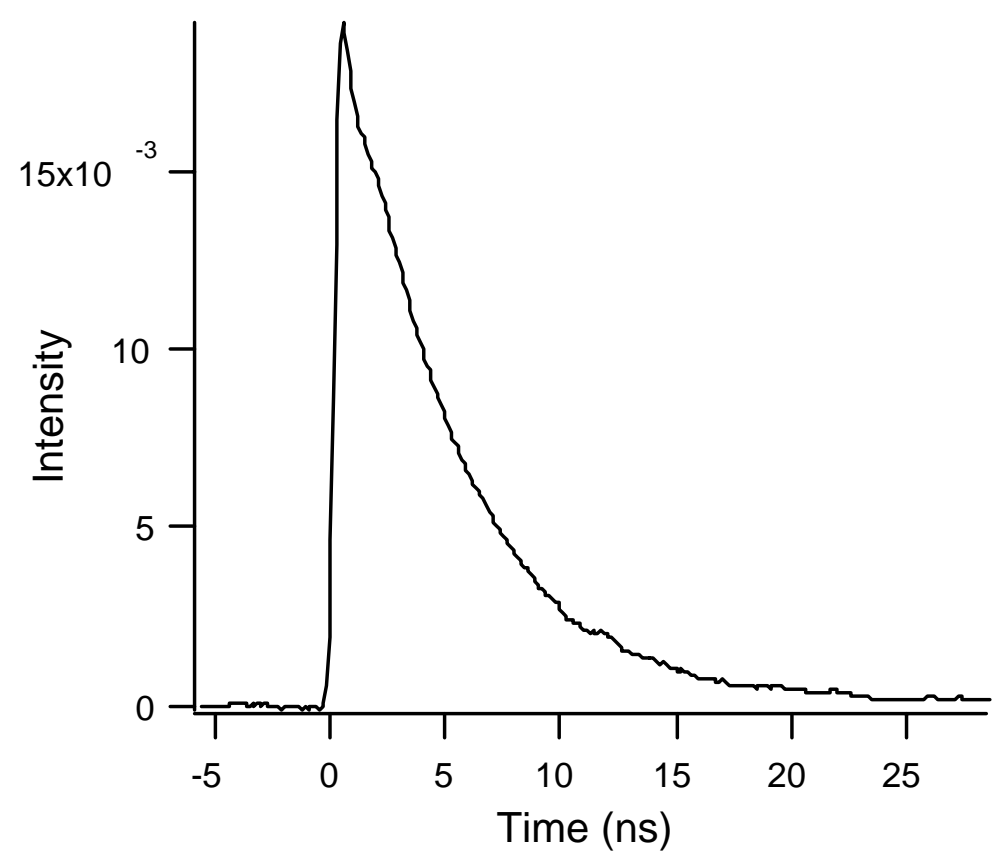

Fig. 4. 

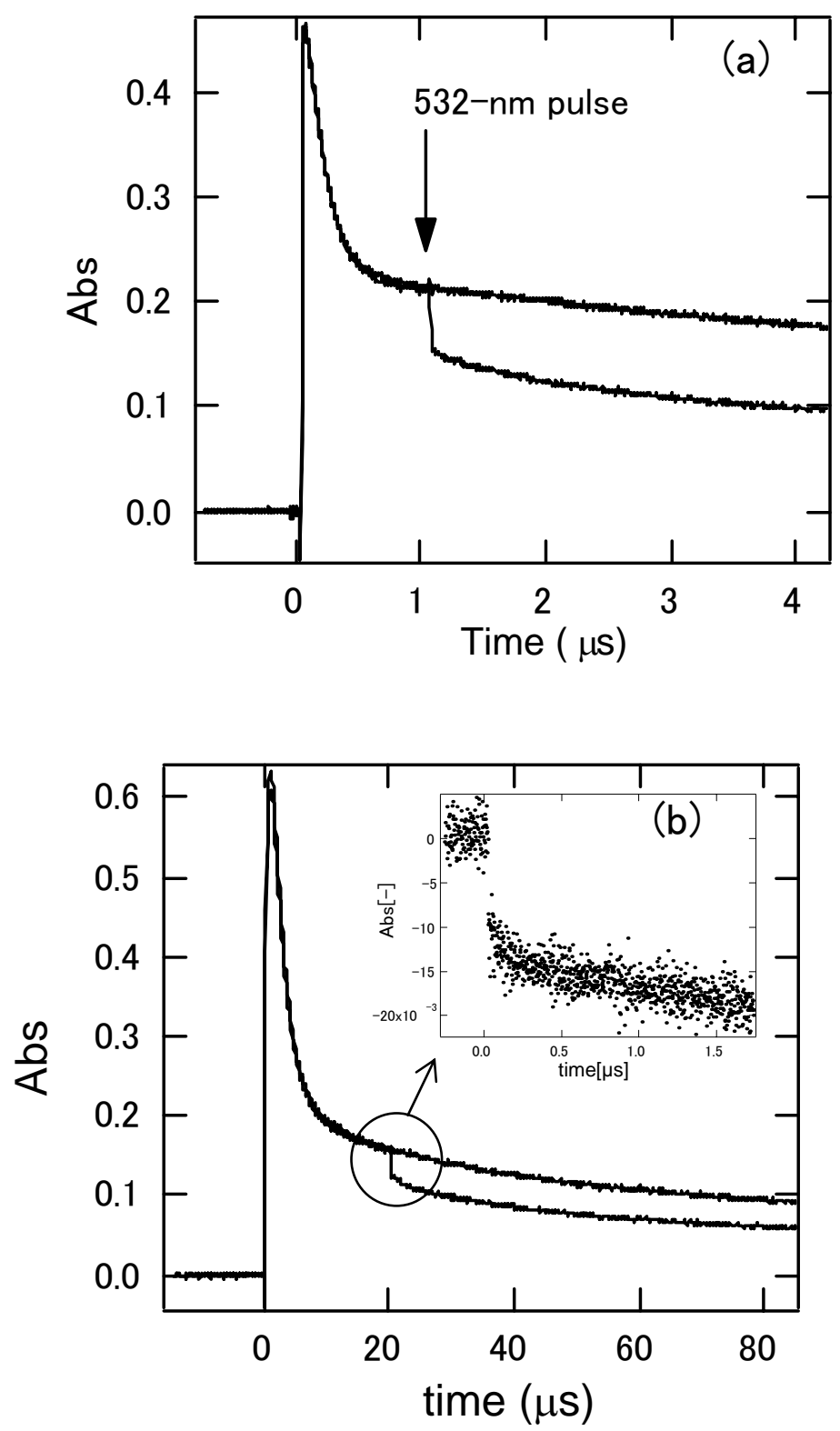

Fig. 5. 


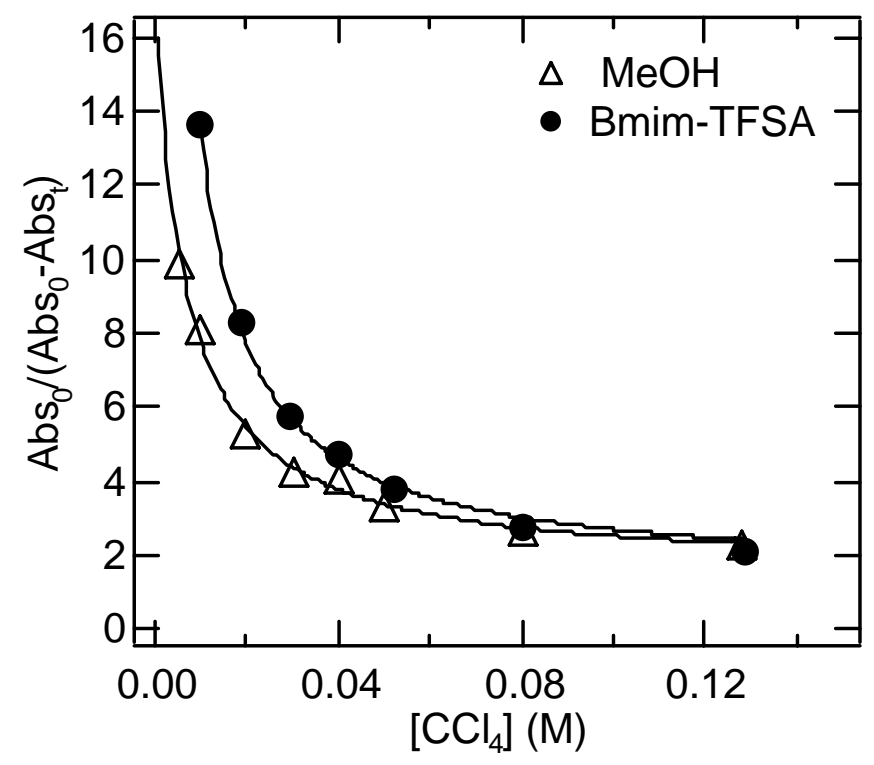

Fig. 6. 
Graphical Abstract

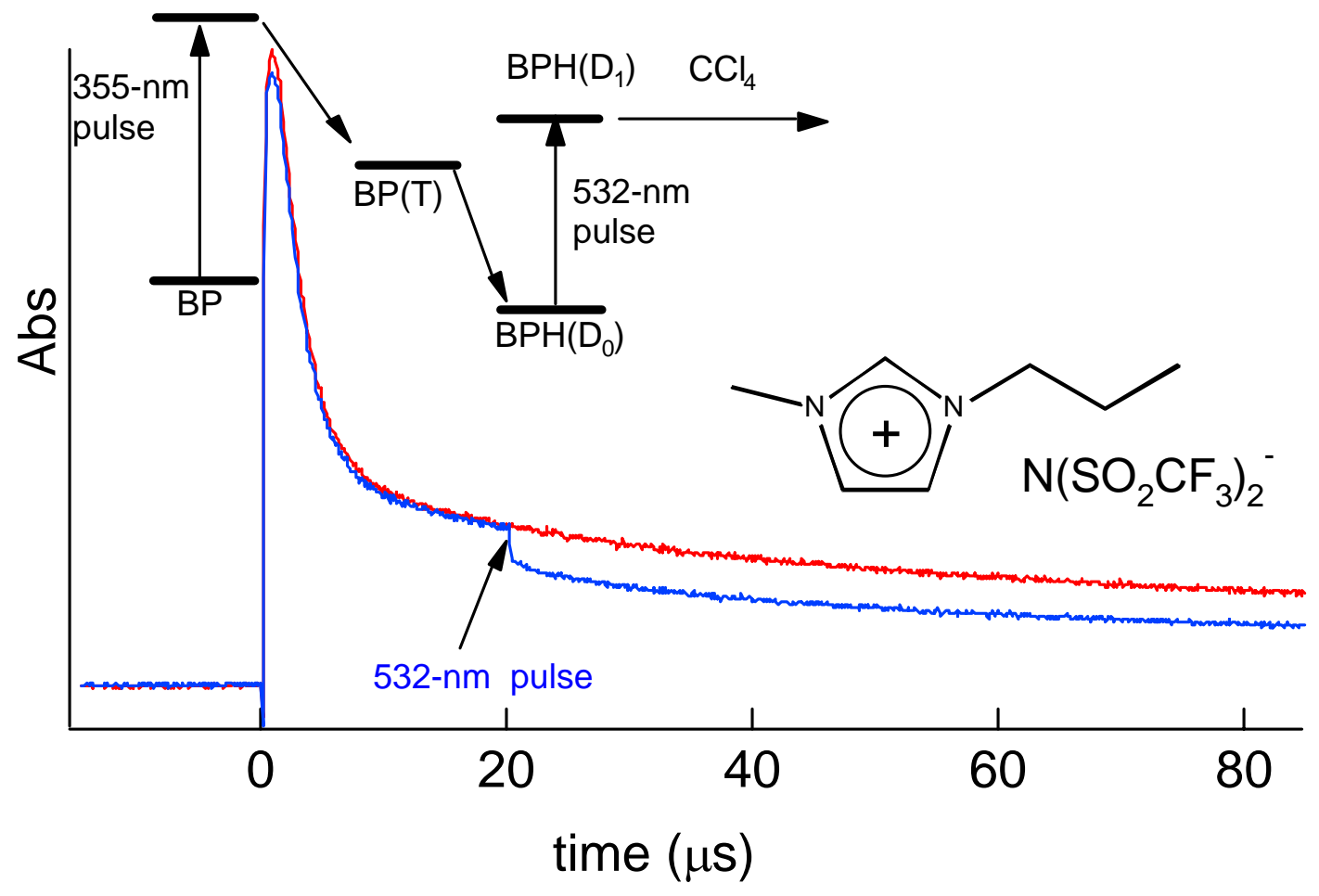

Benzophenone ketyl radical, which is excited by 532-nm laser pulse, reacts with $\mathrm{CCl}_{4}$ in the ionic liquid 1-butyl-3-methylimidazolium bis(trifluoromethylsulfonyl)amide. 


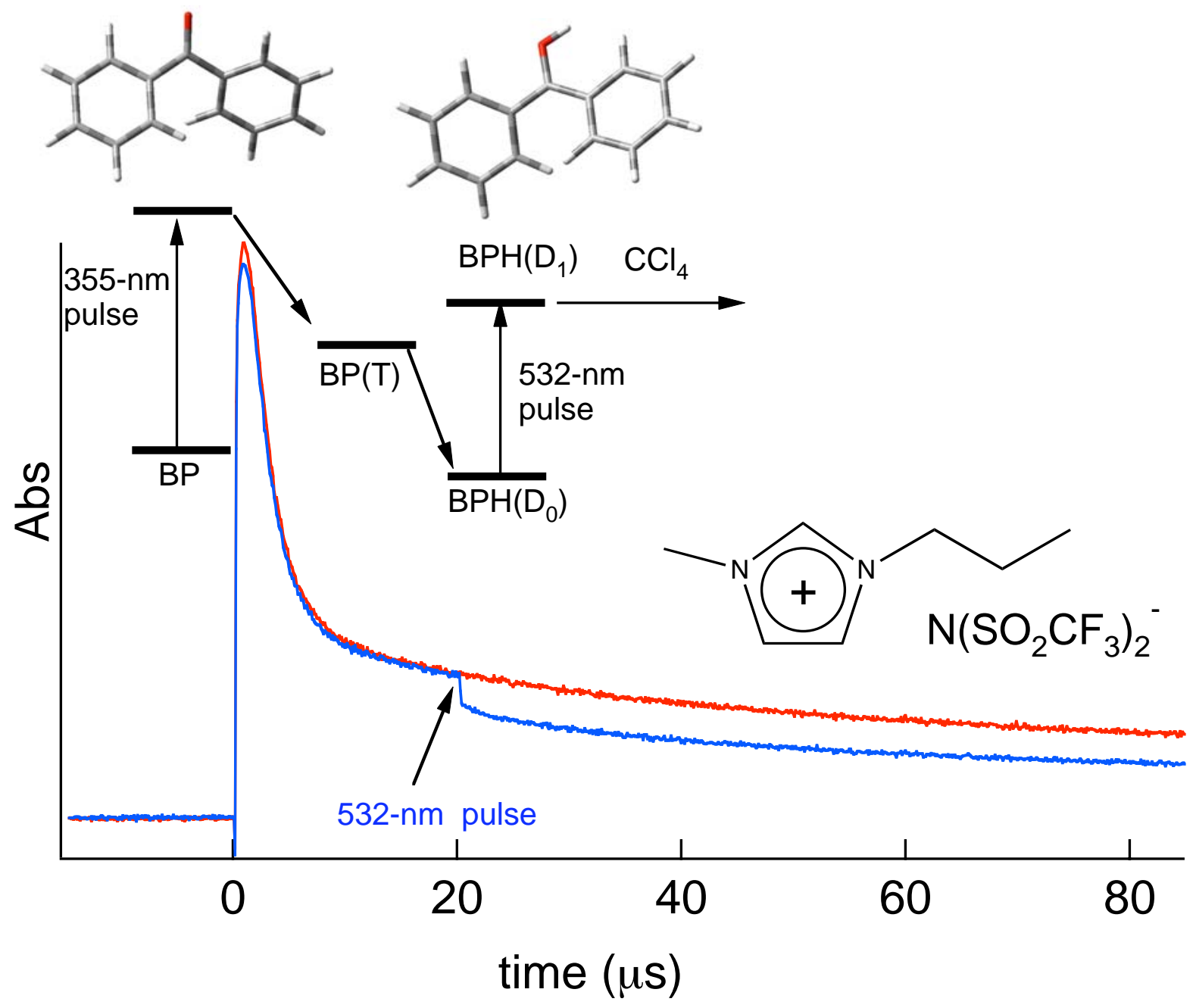




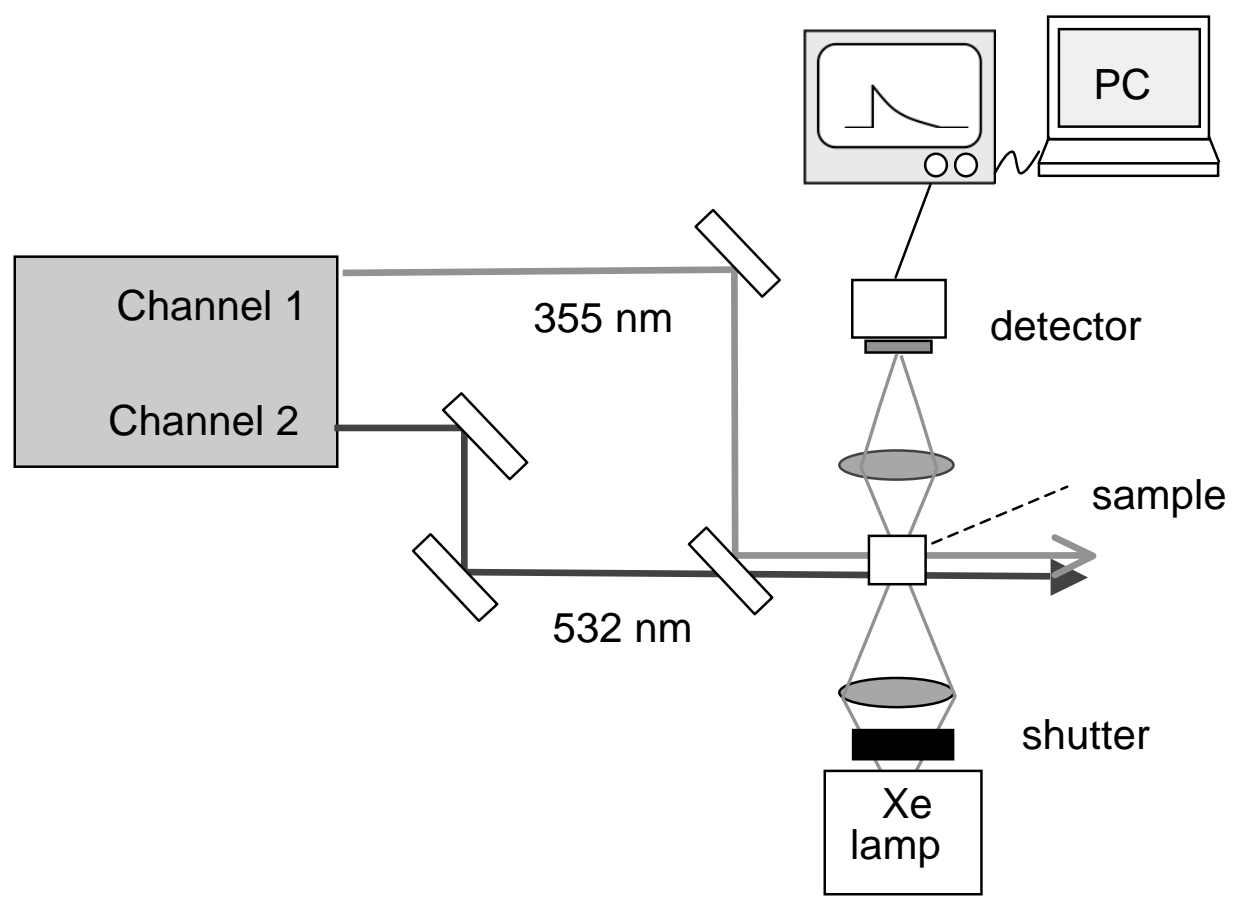



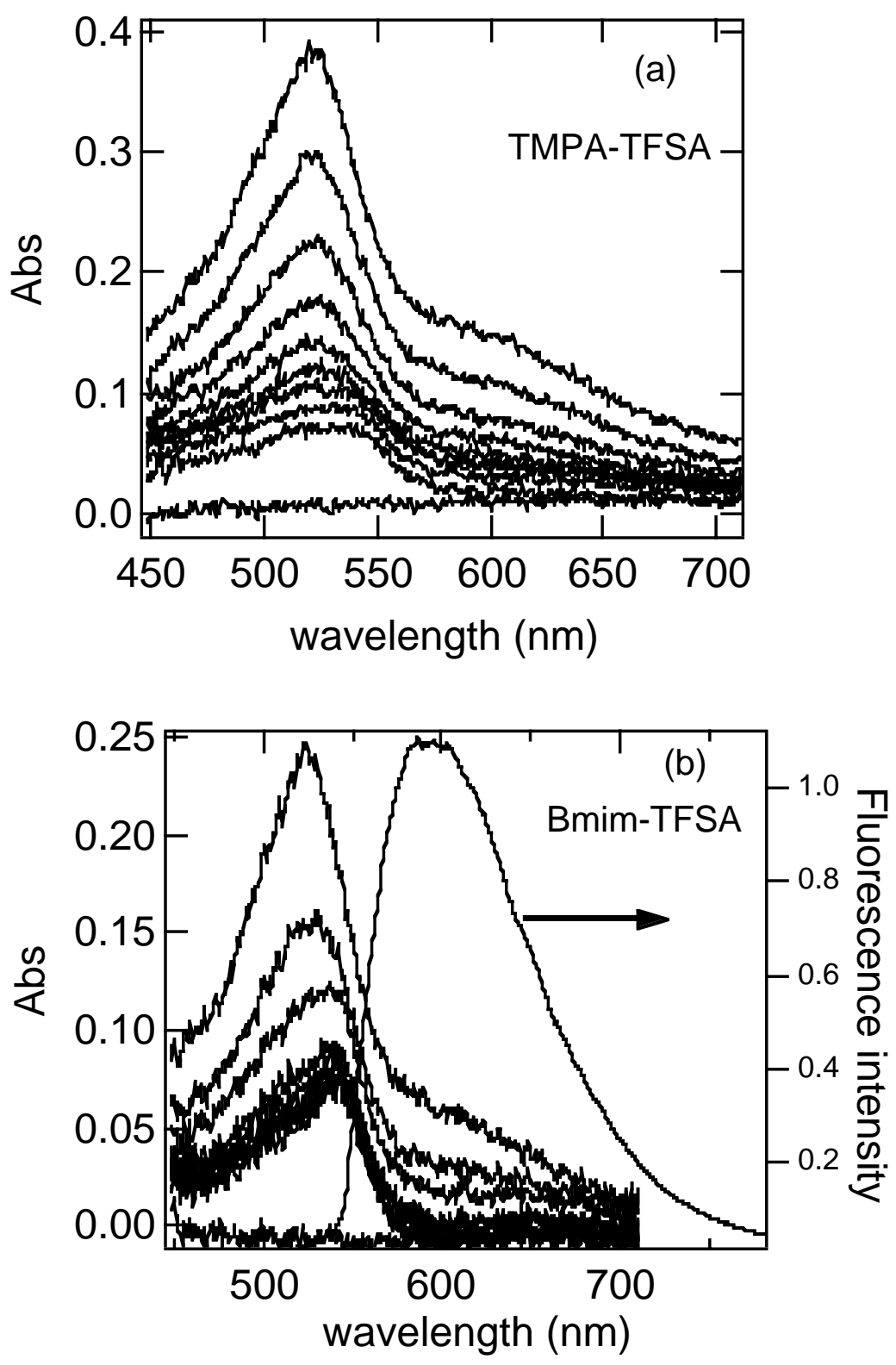


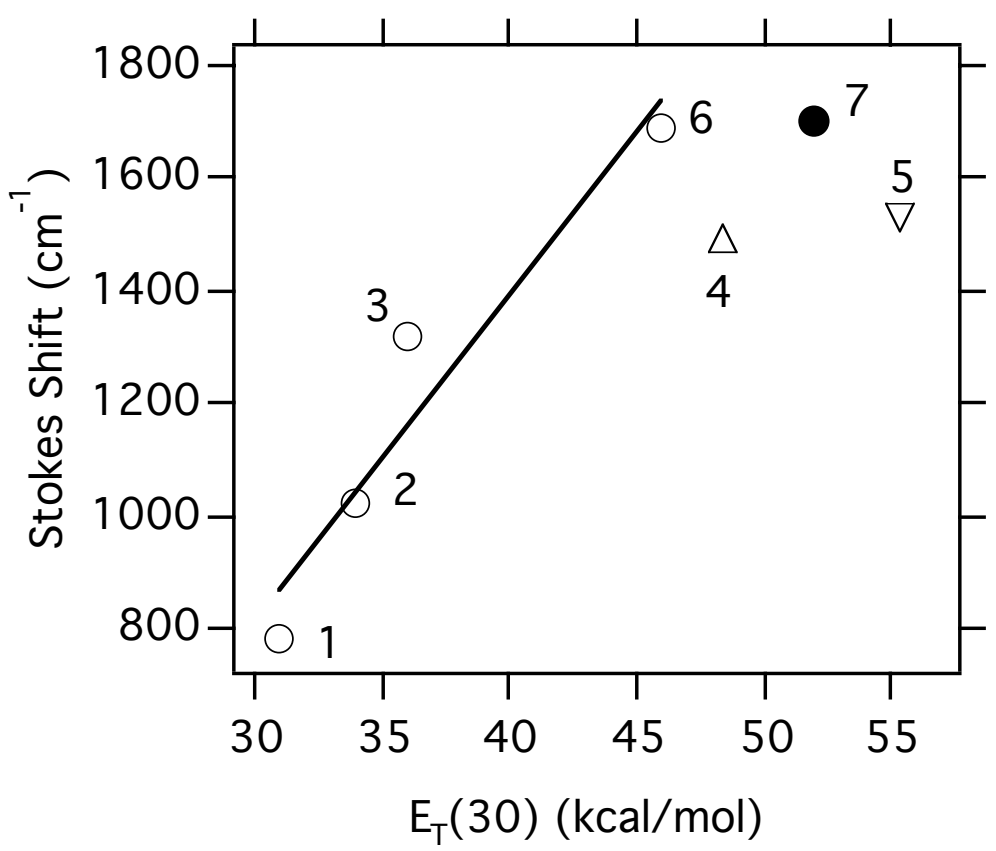




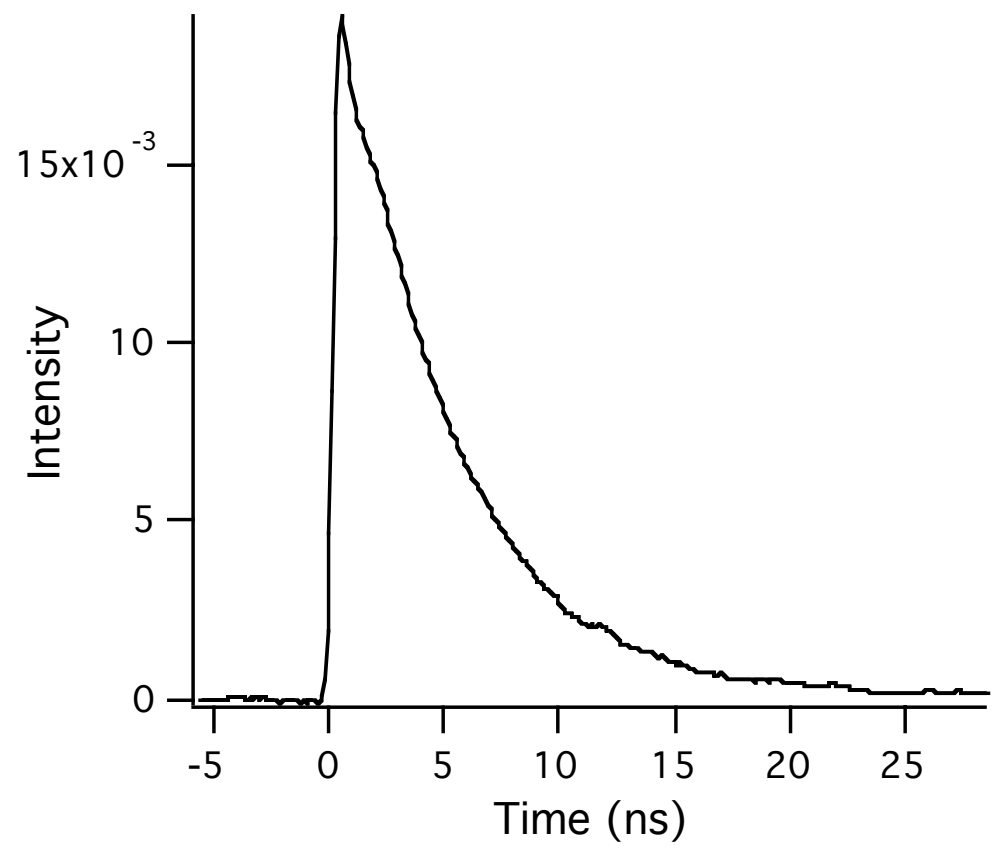



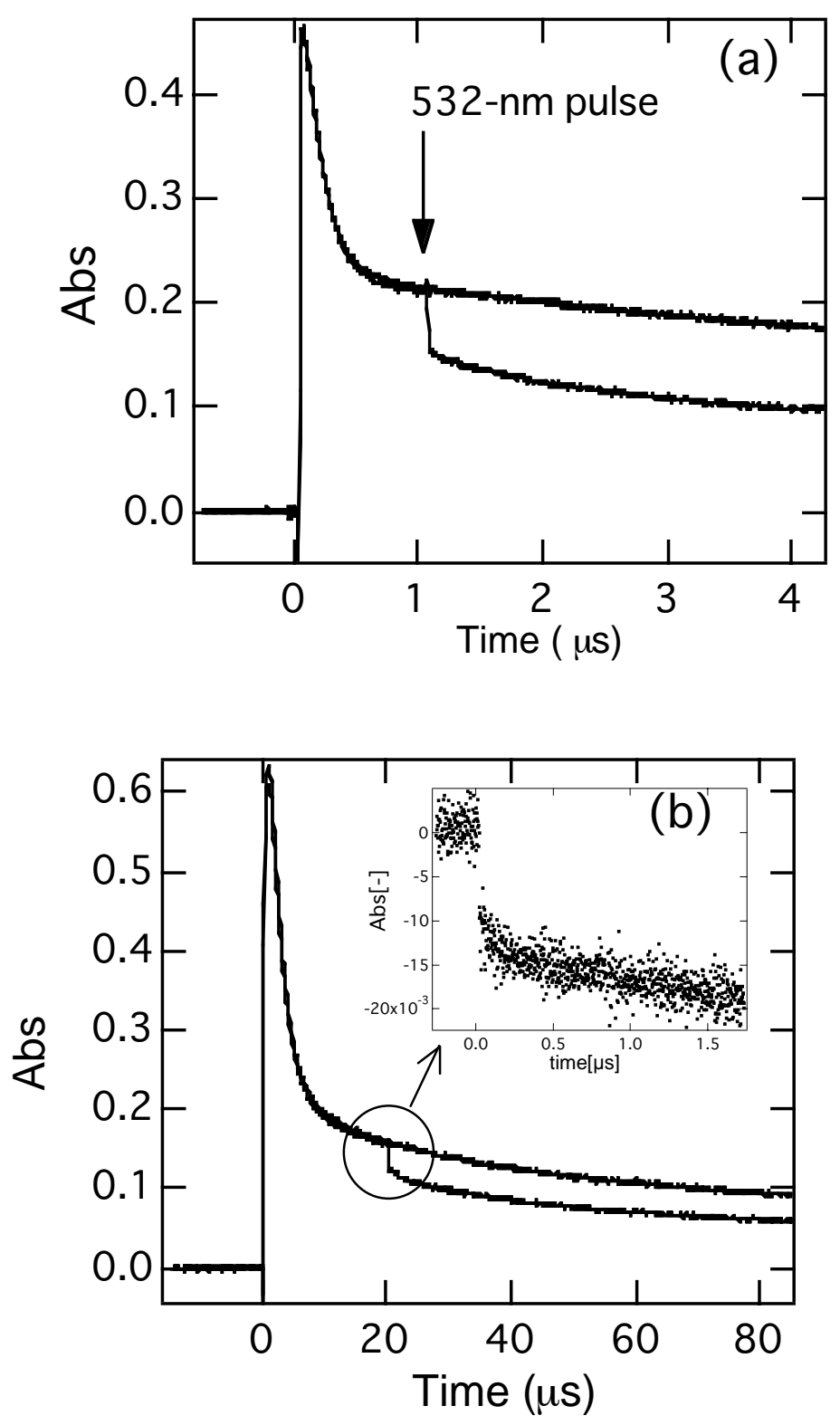


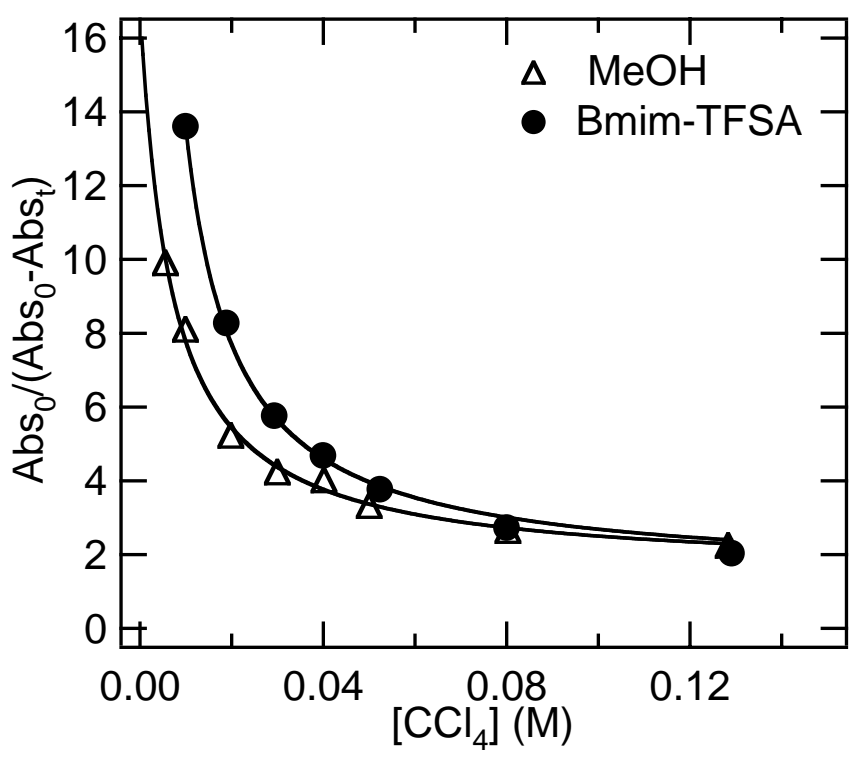

